The Version of Record of this manuscript has been published and is available in Culture and Organization (2015), http://www.tandfonline.com/doi/full/10.1080/14759551.2015.1075539

\title{
Deconstructing divisions: Cultural schismogeneses as sources of creativity in organizations
}

\author{
Meta Gorup and Dan Podjed
}

Drawing on Gregory Bateson's theory of cultural schismogenesis, the authors analyse such processes within two organizations: the Birdwatching and Bird Study Association of Slovenia and VU University Amsterdam. Both cases illustrate internal cultural divisions typical for non-profit organizations whose goals go beyond optimizing financial profits and can thus be interpreted in various, sometimes conflicting, ways. The article demonstrates how organizational members, through continuous processes of creative deconstruction, transform organizations by simultaneously creating both schisms

and coalitions. This shows that, although cultural divisions may at first glance seem destructive, they are at the same time sources of creativity that permit organizational renewal and growth.

Keywords: cultural schismogenesis; organizational cultures; creative deconstruction; ethnographic approach; non-profit organizations

\section{Introduction}

There have been several analyses of cultural differentiation and consequent divisions in organizations (e.g. Boje 1995; Gregory 1983; Rosen 2000), but case studies presenting details on schisms and their evolution have so far not been carried out. Cultural schismogenesis has been defined as 'progressive differentiation' occurring due to discrepancies between members of various groups or within a single community (Bateson 1935, 181). In its simplest version, it describes polarizing social processes wherein differentiation between individuals develops through their interactions - for example, a passive person becomes increasingly inactive in his or her encounters with an aggressive individual (Blackwell Reference Online 2014). This phenomenon, which can be extended to social groups, has been explained on the basis of cybernetic systems theory. This theory explains positive feedback loops wherein one element acts on the other and vice versa, which creates increasingly apparent differentiation between them (Wiener [1950] 1954).

This article proposes looking at multiple cultural schismogeneses in organizations as simultaneously destructive and constructive processes; in other words, as processes of creative 'deconstruction' (Derrida [1967] 1998). We explain that organizations facing cultural schismogeneses are actually involved in iterative processes of creative deconstruction through which organizational members deconstruct and interpret their social realities depending on their personal and group worldviews and, in so doing, simultaneously create schisms and maintain a certain level of equilibrium. From this perspective, we use deconstruction as an approach that explains cultural schismogeneses in 'complex organizations' (Czarniawska-Joerges 1992) not just as counterproductive or even destructive processes, but also as a generative and constructive element in the (re)creation of organizational culture, which we understand not as a monolithic entity, but rather as a process of constant struggle for prevalence between different organizational factions (Parker 2000).

The inspiration to look at cultural schismogeneses in organizations as processes of creative deconstruction originates from our fascination with M. C. Escher's famous woodcut print 
Metamorphosis II, which portrays seemingly opposing 'streams' of figures actually representing the sources for new ones. Bees, birds, and fish, colliding in the centre of the image, seem to originate from one another, and one figure needs to be reshaped for another to be created. We contend that organizations face similar processes: encounters between different organizational cultures may result in schismogeneses, but at the same time they provide sources of organizational balance and creation. This article explores such processes through ethnographic studies of two organizations that have faced cultural schismogeneses: the Birdwatching and Bird Study Association of Slovenia (DOPPS) and VU University Amsterdam in the Netherlands (VU). ${ }^{1}$ These have both experienced internal divisions and consequent transformations due to a large variety of interpretations of organizational goals related to their non-profit nature and the specifics of their management (Drucker 1990). In both cases, schismogeneses resulted in an iterated transformation, providing us with a good starting point for comprehending what occurs when organizations encountering cultural schisms are required to reinvent themselves in terms of their 'basic assumptions' (Schein [1985] 1992) through simultaneous transformation of their values (Hatch 1993).

The first case presented describes such a transformation in the DOPPS, an ornithological and nature conservation association formed in the late 1970s. Its complex structure combines voluntary efforts and professional work. Initially a purely voluntary organization, the DOPPS was transformed in the late 1990s into a semi-professional one, consisting of approximately 1000 volunteer members and employing more than 20 people. This article outlines the association's transformation from a volunteer association to an organization integrating volunteers and professionals while emphasizing the dynamic and unfinished nature of the change process (see Podjed and Muršič 2008).

The second case study analyses change at a university in the Netherlands: the VU. The VU has been going through a change process characterized by the introduction of strong central leadership, decreased academic self-governance and autonomy, and business-like behaviours striving for more effective and efficient organization. These new values are not in line with what is believed to be characteristic of 'traditional' universities, in which collegialism and academic autonomy should thrive. In spring 2012, some university employees started overtly challenging the changes, which made the already present cultural schismogenesis between managerial and academic cultures even more apparent. However, these perhaps most obviously contrasted values have resulted in further schismogeneses in the organization.

The two case studies illustrate that internal ambiguities, conflicts, tensions, and differentiations not only create organizational divisions but are at the same time sources of new coalitions that allow organizations to maintain a certain organizational balance despite (indeed, precisely because of) organizational change processes, whether planned or otherwise. Thus this article contributes to understanding how organizational change evolves and what the unexpected consequences of such processes may be. These findings are relevant not only for further research and analysis of transformations in organizations, but also for management of dynamic cultural processes and changes in organizational settings.

\footnotetext{
${ }^{1}$ Organizational cultures of the DOPPS are presented in detail in Podjed (2011). The analysis of the VU is based on the unpublished master's thesis of the first author (Gorup 2013).
} 


\section{Theoretical framework}

The theoretical framework draws on three concepts: cultural schismogeneses, organizational cultures, and creative deconstruction. The first helps explain how different cultures within organizations come into contact during which, due to their differences, schisms often emerge. To comprehend cultural schismogeneses in organizational environments better, the notion of organizational culture is then introduced. We argue that organizational cultures should be discussed in the plural and that they should be understood as dynamic processes. These two concepts point in turn to the usefulness of the creative deconstruction approach, which emphasizes the non-singular nature of truth by explaining that social reality, be it organizational or of any other sort, cannot be understood outside a certain context. Hence, in the process of deconstruction, individuals or groups destroy and construct characteristics of a given social reality, and in so doing simultaneously create schisms between some entities and alliances between others.

Culture in this text is understood, broadly speaking, in a contemporary anthropological sense that usually understands culture in the plural; as ways of life, socially acquired behaviour, and knowledge (e.g. Kuper 1999). Encounters between different cultures have long been of interest to scholars studying the not-always-peaceful dynamics of cultural contacts. Theorizations of the 'cultural schismogeneses' that such cultural encounters often resulted in were initially introduced by the English anthropologist, semiotician, and cyberneticist Bateson (1935), who defined them as splits or divisions between strongly opposed sections or parties, caused by differences in opinion or belief. Bateson not only recognizes the possibility of cultural schisms between different cultures, but also finds them within a single community, which is particularly relevant for our analysis of the two organizations presented here. He proposes three possible outcomes in the event of culture contact: 'the complete fusion of the originally different groups, the elimination of one or both groups, [or] the persistence of both groups in dynamic equilibrium within one major community' $(1935,179)$. Differentiation can lead either to a schismogenesis or to the establishment of an equilibrium, although Bateson does not pay further attention to how this equilibrium may be maintained.

This conceptualization of cultural encounters can also be applied to organizational contexts. In line with the above, a schismatic metaphor in organizations is used by Morgan (1981), who argues that organizations fundamentally lean towards disintegration as an outcome of change generated from within. He combines two possible views of a schism. The first contends that units of a system 'strive for functional autonomy' (Morgan 1981, 25) and independence, and the second refers to a schismogenesis in which interactions between different groups may actually generate unity and do not result in a breakdown. Introducing a postmodern view of cultures in general, and organizational cultures in particular (Parker 1995, 2000), we argue that schismogeneses and equilibriums are actually part of the same process.

Organizational culture has been a contested notion, and its researchers have defined it in various ways. In analysing various approaches to organizational culture, Martin (2002) outlines three possible viewpoints. The first, the integration perspective, argues that culture is a monolithic entity, perceived and shared in very similar manners among all organizational members (e.g. Deal and Kennedy 1982; Ouchi 1981; Peters and Waterman 1982; Pettigrew 1979; Schein [1985] 1992). The second, the differentiation perspective, recognizes that there are ambiguities within 
organizations, but acknowledges agreement at the subcultural level (e.g. Alvesson 1993; Brooks 1999; Gregory 1983; Rosen 2000). The last, the fragmentation perspective, argues that ambiguity is central for understanding culture. Individuals perceive their social realities in different ways and collective consensus cannot be reached (e.g. Daft and Weick 1984; Hatch 1999). We wish to adopt a combination of the last two perspectives on organizational culture, while particularly stressing two of its characteristics: plurality and fluidity.

Organizational culture, rather than being uniformly shared, is a constant struggle for prevalence between various factions, coalitions, or subcultures, which all try to define common organizational aims in their own ways. It can be understood as a 'continually contested process of making claims of difference' in groups and between them (Parker 2000, 233), and can thus be viewed as a 'struggle for hegemony' with competing oppositions attempting to define the primary purpose of the organization in a way that meets their definitions (Parker 2000, 75). From this perspective, which is in accordance with anthropological definitions of culture (Batteau 2000), organizational culture is not stable and permanent, but instead constantly being enacted and changed. In line with this definition of organizational culture, it is important to grasp that cultural transformation and change are virtually uncontrollable because they are results of 'simultaneous interlocking local processes' (Demers 2007, 88). Such a perception of organizational cultures, with an emphasis on ambiguity as a way of life - which probably fits best into 'fragmentation studies' (Demers 2007, 88-89) - implies that organizations can be seen as undergoing a constant and unfinished process of deconstruction. Their realities are understood and interpreted in different ways and are often contradictory, and this is why cultural schisms emerge. At the same time, however, it is exactly these schisms that are necessary to maintain an equilibrium because coalitions are formed through this same process. Although schisms result in strained relations between some groups, this may at the same time cause closer connections between members within set groups. Schisms not only imply new divisions, but also (and always) new alliances. From this perspective, organizations are simultaneously undergoing processes of creation and destruction.

This leads to the concept of creative destruction, which was introduced in economics by Schumpeter ([1942] 2003). This describes the continuous destruction of the old and the creation of a new economic structure within the system, caused by the introduction of new products, methods of production, markets, and forms of organization. The concept has also been applied to organizational studies. Biggart (1977), for example, shows that, in order for an organization to change, destructive and creative processes must coexist, this referring to the destruction of old work methods, facilities, technologies, alliances, and organizational ideology having to coincide with the creation of new forms of these elements. Similarly, Cule and Robey (2004) illustrate the importance of the creative destruction phase in organizational transition.

Although Schumpeter's ([1942] 2003) notion of creative destruction offers valuable insights into the ways in which organizations change, we maintain that the processes of creation and destruction in organizations can be better understood through the process of 'deconstruction'. The concept of deconstruction was introduced by Derrida ([1967] 1998), who defined it as an approach to studying texts based on the assumption that language is a system of differences. A word cannot be understood without having a comprehension of its opposite, and it is therefore 
through this différance ${ }^{2}$ that an understanding is reached. Thus one can only understand a word if one understands its context - a word's meaning depends on the context in which the reader, writer, or speaker has placed it. Hence the same word can be understood in almost countless different ways, as individuals ascribe meaning to it depending on their own frames of reference. Consequently there exist no objective meanings of words, and indeed the majority of texts comprise narratives that are conflicting or contradictory. It is through the process of deconstruction that these inconsistencies are exposed, which points to the fact that deconstruction stands for simultaneous and continuous construction and destruction. This complements Schumpeter's ([1942] 2003) notion of creative destruction by recognizing that the seemingly separate processes of creation and destruction may in effect be seen as convergent. A similar approach can be applied to social and organizational phenomena or, as in the case at hand, to the different understandings of organizational cultures and consequent cultural schismogeneses.

\section{Research methods}

Both researchers carried out ethnographic research consisting of participant observation, semistructured interviews, and focus groups. Participant observation encompasses the active involvement of the researcher in the activities of the groups of people studied; in combination with other research approaches, such as semi-structured interviews, the researcher immerses himself or herself in the lives of the researched (Prasad 2005) - in this case in organizational life - in order to follow the daily activities, rituals, interactions, and events of the people being studied as one of the means of learning the explicit and tacit aspects of their cultures (DeWalt and DeWalt 2002). Thus the researcher is able to provide in-depth and 'emic' insights into the topic studied while being context-sensitive (Ybema et al. 2009). One of the main challenges - and at the same time the primary interest - of our ethnographic research was that organizations and their cultures are in constant flux. Hence it was of crucial importance not to look at and represent these phenomena as 'frozen social form[s]', but instead to think and write about them as occurrences in a 'state of organizing in itself' (Garsten 1994, 217). Ethnography is a particularly relevant approach if one is to understand and analyse organizations as dynamic social entities because it aids in describing separate partitions in time, and consequently understanding their transformations.

To provide a quality interpretation of data, a coding-based analysis was carried out. Coding is a way of looking for patterns by categorizing language in use (Taylor 2001), and it enables the researcher to systematically define what the text analysed is about (Gibbs 2007). Both researchers created combined analytical frameworks, meaning that they interwove interview transcripts and field notes. This significantly improves the quality of analysis because it makes it possible to discover both the differences between and the complementarity of the various types of texts (Lastovicka and Fernandez 2005; Strøm and Fagermoen 2012).

Despite the similarities in research approaches, there are several differences between the two case studies. The main part of the ethnographic study of the DOPPS was carried out from January 2006 to January 2008. The research took place several years after a significant organizational change had occurred in 1999. During the main part of the ethnographic study, the researcher accompanied the birdwatchers on their field trips and participated in their formal and informal

\footnotetext{
${ }^{2}$ In coining the term différance, a play on words was used to explain that a meaning is constantly 'deferred', that is, postponed, and simultaneously 'differentiated' in relation to other elements.
} 
meetings, educational training, and nature conservation activities. He not only observed, but also took part in, beginner training, bird counts, and other volunteer activities; by so doing, he was carrying out 'engaged learning' (Carrithers 1992). He carried out 30 semi-structured interviews (each lasting one hour or more), of which six were with DOPPS employees (one interview was repeated in order to gather additional information), four with executive board members (one was repeated), one with a supervisory board member, two with heads of regional branches, one with a former member and the main founder of the DOPPS, and 14 with volunteer members. He also conducted two focus groups: one with members of a local branch and the other with teenage participants at an ornithological camp. After the main part of the ethnographic study was concluded, he carried out several unstructured follow-up interviews in order to collect additional information.

The main part of the research at the VU was conducted between February and May 2013, which was a period characterized by turbulent real-time organizational turmoil. The research was partly retrospective and partly real-time, analysing in detail the period between March 2012 and July 2013, when several cultural schisms within the organization had become prominent. It has to be noted, however, that the turmoil at the university studied continued after the researcher left the field. The researcher attended four public events and eight informal meetings held by the opposing university staff. In so doing, she gained an understanding of how the resistance movement functioned and their perceptions of the various cultural schisms emerging within the organization. In addition, she conducted 22 semi-structured interviews (average duration of about an hour), of which 14 were carried out with academic and non-academic staff involved in the opposition to change, two with deans, one with a senior director, one with a project officer of the operations programme, one with a policy advisor, one with the chair of the works council, one with the chair of the students' council, and one with a student that supported the employees in opposition. Interviews with some representatives of the university management provided insights into their perspectives on the organizational transformation under study. The researcher also conducted a focus group among students at the Faculty of Social Sciences who expressed interest in participating in activities aimed at improving the quality of education.

The case studies presented are complementary in that they illustrate the same processes occurring in two organizations characterized by conflicting perceptions of organizational goals caused by their non-profit nature. However, they do so by using different research designs and forms of analysis. The DOPPS was not directly studied during a turbulent period of transformation. Instead, the case study offers an overview of the organization and its change retrospectively and over a longer period of time. The analysis of the VU, on the other hand, was conducted during a shorter period of time but, although it provides details on developments during only approximately a year and half, this period was characterized by uncommonly overt tensions and conflicts. The two case studies thus contribute a longitudinal and a short-term perspective on cultural divisions, illustrating on the one hand the mundaneness of cultural schisms in organizations and on the other their long-term effects.

\section{Cultural schismogeneses in a Slovenian birdwatching association}

The Slovenian birdwatching association DOPPS, headquartered in Ljubljana, has over 1000 members. It was founded in 1979 by a group of 76 ornithology enthusiasts, led by a charismatic leader - a former poet and writer who became immersed in amateur ornithology in the 1970s 
through a simple question: What birds can be seen in Slovenia? Because no Slovenian ornithological atlas was available, 'there was no other possibility than to organize it', he explained in an interview. By 'organize it', he actually meant establishing an ornithological association that would involve people capable of carrying out bird counts and monitoring activities (Podjed 2010b). Since then, the DOPPS has grown into the leading Slovenian nature conservation and birdwatching association. It carries out activities nationwide, with five regional branches and a youth branch. The highest ranking official body of the association is its general assembly, composed of DOPPS members. The two other bodies are the executive board, comprising a president, vice-president, delegates of regional branches, and other members, and the supervisory board, which has four members. Since the mid-1990s, the association has also had a professional team: the DOPPS Office, which comprised over 20 employees at the time of the research, including the director.

\section{Background}

The establishment of the association in Slovenia came much later than the founding of similar birdwatching and nature conservation associations in the West; for example, in the UK or the Netherlands. The relatively late formation of the DOPPS can partly be explained by the socioeconomic situation in the aftermath of the Second World War, when the country was part of the former socialist Yugoslavia. In the post-war years, public opinion and politics were not generally in favour of birdwatching or nature conservation. Occasionally, being a birdwatcher was even dangerous, because '[a]nyone who tried to preserve wetlands and old orchards was considered to be an opponent of socialist development' (Trontelj 1999, 1). In addition, when the birdwatchers tried to spot birds with their binoculars around factories or military barracks, on several occasions they were considered potential spies and enemies of the regime (Iztok Geister, in Ahačič 2008, 38).

The late 1980s and early 1990s were marked by the social and political transition of Slovenia, which became an independent country in 1991. Almost instantly - indeed even before the former Yugoslavia had been dissolved - it started to search for new alliances both inside and outside Europe. The collapse of the former country also initiated the disintegration of the Yugoslav Association of Ornithological Societies (ZODJ), which also prompted the DOPPS to start searching for new international connections, especially with BirdLife International, the world's largest nature conservation partnership, with over 13 million members and supporters. BirdLife fully accepted the DOPPS into its international network in 2001. Three years earlier, the name of the association was officially changed to 'DOPPS-BirdLife Slovenia', which both symbolically illustrated the international partnership and at the same time hid the old mission statement described in the association's original name; that is, birdwatching and bird study. At first glance, this was an insignificant change; in effect, however, it marked a transition to a new period, with more emphasis on nature conservation (Podjed 2013).

\section{Internal divisions}

Throughout its existence, the DOPPS has had a clearly defined mission statement (i.e. the protection of birds and nature), but in fact its goals have been interpreted in several ways. In other words, the organization has been 'torn apart' at multiple levels throughout its history (Podjed 2010a). These divisions were gradually reinforced through positive feedback loops, characteristic of schismogenetic processes. Most apparent was the differentiation between the employees who 
began working for the DOPPS office in the mid-1990s and volunteer members of the association, who generally referred to themselves as 'amateur ornithologists'. The latter commonly perceived the employees as privileged members of the organization because they were often paid for doing the same jobs that the volunteers carried out for no pay. As the professional side gradually grew, its growth reinforced opposition on the part of the volunteers, and the division between the groups became more apparent.

The second schism was caused by generational differences; that is, by gradual ageing of its existing members and incorporation of younger newcomers, who transferred new ideas and values into the organization. Initially, in the late 1970s, the association was a relatively unstructured community with a flexible and unclear hierarchy, and it was also an association of colleagues of similar age. A founding member explained that at that time there were "no clear commands' and 'everything was jointly agreed upon: how to attract new members, how to enrich the journal, and so on'. Gradually, however, the group of older members remained more focused on the original core activity of the DOPPS (i.e. birdwatching), while the group of younger members supported more professional, organized, and structured work and emphasized the need to move towards more socially and environmentally relevant activities (i.e. nature conservation). During ethnographic research carried out in the 2000s, a comparable generation split was identified: the youngest members, that is, representatives of the third generation, commonly acted as a homogenous group that stood up against the principles of the middle group (the former group of young members). In addition, the youngest generation started to reconnect with the oldest generation and therefore formed a new, 'mixed' group.

The third schism was created at the beginning of the organization's existence on the basis of knowledge about birds and nature. Some DOPPS members - both professionals and volunteers are extremely skilled at bird recognition and in zoology and botany. On the other hand, many other members, especially the newcomers, do not know much about birds and their behaviour, but simply enjoy walking in the countryside and spending time with like-minded people. The problem here is that skilled and unskilled members have to cooperate and help each other when they carry out bird monitoring and nature conservation activities, which can cause tensions between the two groups.

The fourth schism occurred on a geographical basis or, more specifically, due to tensions between the central region of the country and the periphery. During the research, it was frequently mentioned that the DOPPS had become too centralized and that information travelled only in the direction of the central branch in the country's capital, Ljubljana. This perception of 'underprivileged members' at the periphery has also led to several clashes and has reinforced the internal divisions.

\section{Managing change}

Tensions between the various groups in the DOPPS came to a head in 1999. The trigger for change - which was often referred to as a 'revolution' - was a seemingly irrelevant dispute over the finances for printing the association's journal. Due to inappropriate financial management, the DOPPS executive board decided to replace the chief editor of the journal, who was also the charismatic founder of the association and the informal leader of the 'older generation'. Thus the founder lost his position of power in the association and consequently severed his contact with it. 
This unexpected farewell of the 'founding father', as he is often described by his (former) colleagues (and even by younger birdwatchers who had not met him in person), indicated that a clash between old and new values had occurred. However, this event was only a manifestation of schismogenetic processes in the organization; it was triggered by several events and activities and followed by other, perhaps less apparent, transformations. In the mid-1990s, the association managed to attract an important general sponsor: a mobile telecommunications company. Then, in the 2000s, it became involved in several important EU nature conservation projects; for example, a project to renature a coastal bay and a project for conservation of an endangered bird species, the corncrake. Moreover, the DOPPS made a shift from volunteer research and amateur birdwatching to nature conservation carried out on a more professional basis.

In the 1990s, new values in the association and a new organizational model, aimed at solving the schisms within the association, were demarcated by the arrival of a new director (i.e. office head). Prior to taking his executive position in the DOPPS, the new director was an amateur ornithologist, closely involved in nature conservation, and employed as the manager of a forprofit company. In the interview, he explained that his managerial skills, honed in the for-profit sector, proved very useful in the DOPPS because he soon realized that the professional team (the office) could be managed in a way similar to how mainstream companies are managed. However, there is also a crucial difference between the for-profit and non-profit sectors that has to be taken into account. In the interview, he described the main difference:

In a company, you always know who holds the reins. The reins are held indirectly, through management. Those decision-making lines are clear. But in the association, these lines are less transparent. The reason is this: members elect the executive board, which makes decisions about the main strategies and so on. In addition, all the employees are also members of the association.

According to the director, there is a highly motivated group of both volunteers and professionals in the DOPPS:

It's not difficult to motivate them. In a company, people soon begin avoiding work. /.../ There, you have to make sure that people work. But here everything's different. Because people are highly motivated, they take on more work than they can manage.

This implies that a manager in such settings should actually motivate people to work less than they would otherwise want and to support them in distributing their activities in a more focused way. In the DOPPS, such an 'anti-managerial' approach (cf. Parker 2002) was established simultaneously with a turn from observing birds to nature conservation. This was also one of the reasons why the volunteer element stagnated for a while - birdwatching is a popular leisure-time activity, but nature conservation can hardly be defined as such. Moreover, funding of EU nature conservation projects, which covered almost half of the association's budget in recent years, made it possible to strengthen the professional part of the association (i.e. the DOPPS office).

In addition to nature conservation projects as the main activity in the DOPPS since 2000, the association still carries out birdwatching activities. Since 2002, for example, they have been preparing a new ornithological atlas as a volunteer project, comparable to the initial endeavours 
of the ornithologists in the late 1970s - except that this time it is being managed by the professionals in the DOPPS office. As its coordinator explained in an interview, the new atlas was intended to have a similar cohesive effect as the old atlas - 'unification' of the organization and its members, collaborating towards the same goal. However, this unifying goal can once again be interpreted in various ways.

\section{Cultural schismogeneses in a Dutch university}

VU University Amsterdam is one of 14 universities in the Netherlands. It comprises 12 faculties covering a wide range of sciences and enrolling approximately 24,500 students. According to the university's website at the time of writing, the academic and non-academic staff numbered 2764 and 1905, respectively. The university is governed by five bodies: a supervisory board, an executive board, a college of deans, a works council, and a students' council. The supervisory board (representing external stakeholders) and executive board are the core decision-making bodies. The latter consists of the chair, rector magnificus, and a board member. The college of deans is presided over by rector magnificus and is responsible for overseeing scientific quality and integrity. The works council and students' council are advisory bodies representing university employees and students, respectively. Individual university employees' rights are of concern to the trade unions. The faculty-level governance structure mirrors the central one, with individual deans chairing the core faculty decision-making bodies (i.e. faculty boards).

\section{Background}

To understand the organization of the VU and the cultural schismogeneses overtly emerging in particular since spring 2012, one needs to acknowledge the broader changes that occurred in modern Dutch higher education. In the 1960s and 1970s, Dutch higher education faced notable massification, which resulted in greater government regulation. Nevertheless, academic autonomy was left largely intact. Gradually, universities became perceived as overly separated from the broader society (De Boer, Enders, and Leisyte 2007; Westerheijden, De Boer, and Enders 2009). The late 1970s and 1980s brought about a worsening financial situation, resulting in budget cuts and a reorganization of the public sector, referred to as New Public Management, which placed emphasis on more effective and efficient functioning of public organizations (Pollitt and Bouckaert 2004). In the case of Dutch universities, this meant that they had to become more autonomous and self-responsible, which was to be achieved by shifting from government regulations to output supervision or 'steering at a distance' (Kickert 1995). In effect, this meant that universities had to become more 'market-' and 'output-oriented', which has allegedly also had negative consequences for teaching and learning practices (Bal, Grassiani, and Kirk 2014). These changes coincided with the centralization of university management because the previously decision-making employee and student representative bodies were turned into advisory bodies (Westerheijden, De Boer, and Enders 2009).

The VU had been continuously affected by these processes, but in spring 2012, approximately a year before the ethnographic study took place, particularly heated discussions related to the university's strategic plan started taking place. One of the main issues was the proposed operational reorganization involving a E33 million budget cut to be achieved by centralizing and modernizing administration and support services by the end of 2015, which would result in several hundred layoffs of non-academic staff. As a response, an informal platform for distressed university staff, the 'Concerned VU employees' (in Dutch: Verontruste medewerkers van de VU, 
hereafter VVU'ers), was established. In cooperation with the works council and the trade unions, the VVU'ers organized several events: demonstrations, an 'alternative' opening of the academic year, and a symposium - all raising awareness of the changes that they perceived as worrying.

On top of the proposed budget cuts, major campus renovations started, requiring significant investment. In addition, representative and governing bodies started discussing a proposed merger of science faculties of the VU and of the University of Amsterdam, which could arguably cause further layoffs and, as some saw it, negatively affect the quality of education and research. January 2013 brought a negative trial audit assessment by the Accreditation Organisation of the Netherlands and Flanders (NVAO), which signalled that the VU needed to improve the way it was run, especially its education agenda. In spring 2013, the 'management crisis' at the VU was severely criticized in the media and the rector magnificus resigned, explaining that his qualifications were not compatible with the VU's future objectives (Schilp 2013).

\section{Internal divisions}

These developments indicated that the VU had found itself in a vortex of several cultural schisms. One of the most distinct of these, embodied in the formation of the VVU'ers, relates to the differences between university management and employees. As a group uniting academic and non-academic staff, the VVU'ers emphasized that the policies and strategies of university management signalled the colonization of the VU as a scientific institution by an irreconcilably different managerial culture driven by financial and marketing incentives. According to their manifesto, the VU was turning into a 'cookie factory', where knowledge was reduced to a quantifiable, marketable product and where employees did not participate in the decision-making related to the university's core activities (for an analysis of similar developments in the UK, see, for example, De Vita and Case 2014).

The formation of the VVU'ers simultaneously resulted in a deeper abyss between university employees and management and an alliance among previously rarely connected academic and non-academic staff. As one academic and VVU'er summarized it, 'It was in fact quite new, exciting, and atypical that we [academic and non-academic staff] cooperated in the first place in this, as VVU'ers.' In the words of another academic and VVU'er, 'in the end, we just have to focus on the fact that we [academic and non-academic staff] are dealing with one executive board'. In addition, VVU'ers were cooperating with the two employee representative bodies, that is, trade unions and the works council, and many VVU'ers were also members of one or both official representative bodies.

Despite the commonalities and seemingly shared values and goals, however, several schisms emerged among the VVU'ers themselves. Academic and non-academic employees were subject to different working conditions and different hierarchies of work relations, giving the former more freedom to speak up. At the same time, nonacademic staff were to be directly affected by the changes at the VU, including the layoffs. Whereas many of them were (among other things) fighting for their jobs, the academic staff were not similarly threatened. The different goals of academic and non-academic staff were also reflected in trade union membership. The biggest trade union at the VU consisted of 30\% academic and 70\% non-academic staff. This implied that those trade union members who were also VVU'ers were in essence struggling for individual employees' rights, as opposed to those VVU'ers whose ambitions were mainly related to a structural change in the way in which the VU was run. It was clear that different groups of 
university employees were fighting for dissimilar and sometimes contradictory goals and, although they were sympathetic with each other's approaches and aims most of the time, the differences between them could not be hidden, especially when it came to seeking and reaching agreements with the university management. One academic and VVU'er stated:

It is difficult [for VVU'ers] to have the agenda of the unions to save jobs. . . . I am not going to do that. I'm in favour of that, but I would not say that VVU'ers should have this as their primary task. We support them in that, but I think the union should do it and we're just going to help them; if these were some kind of a solidarity action with the unions, that would be the best model. /.../ So I do think that we should sometimes really make it clear that there are three groups [VVU'ers, trade unions, and the works council] involved here.

The previous set of interrelated schisms implied another split, this time relating to different university sections (faculties and support services). Depending on their sector of employment, employees reacted to the proposed changes differently. In addition to the differences between academic and non-academic staff described previously, it also has to be noted that the majority of the most vocal opponents among academics were affiliated with the Faculty of Social Sciences. This possibly implied a disciplinary schism as well: presumably, social scientists are more socially aware and inclined towards activism than others. Alternatively, this might originate in the fact that the Faculty of Social Sciences was 'threatened' with a merger with the Faculty of Arts in spring 2012, which had raised concerns among some employees.

Furthermore, conflicts also arose as a consequence of the different political affiliations of the VVU'ers. Some VVU'ers were characterized by others as 'hardliners' or 'radicals', suggesting that the best way to achieve their goals was not through negotiation and compromise, but through employing more drastic means of resisting, such as strikes and barricades. Although not averse to public action, the majority of VVU'ers favoured less extreme approaches.

In addition to the parties mentioned above involved in formal and/or informal university politics, students also played an active role. However, students - either through formal representative bodies or via informal student groups - did not form a strong coalition with the concerned employees. According to the chair of the students' council, their motives for and goals of resisting significantly differed from and sometimes even contradicted those suggested by the VVU'ers and trade unions:

As students ... our only concern is what the levels of service, facilities, or education are, and not so much if the employees are getting fired or not. That sounds coldhearted and it is, but sometimes you have to address things like this, otherwise things get mixed up.

\section{Managing change}

In recent decades, universities, including the VU, have faced turbulence, which has resulted in new forms of organization. As a consequence of these changes, tensions between academic and managerial values have become more visible and problematic. In addition, as shown in the previous section, other schisms may occur during times of organizational turmoil. The question remains how these cultural schismogeneses are perceived and put to use in the attempts to maintain organizational balance. 
First, and as mentioned above, a strong coalition, at least at times, was formed among various categories of university employees. Related to this, an alliance between the VVU'ers, trade unions, and the works council was formed. This resulted in a schism between university employees and university management, which caused a shaken organizational balance. Although this did not happen immediately, university management did eventually realize that they needed to provide some answers to their concerned employees. After a stronger resistance movement emerged, the managers directly involved with reorganization plans tried to "clarify to people how the goals of this operation, or project, [were] not contrary to /.../ the nature of an academic organization'. Although such rhetoric is not to be blindly taken as the truth, the interviewed senior director realized that the concerned employees had helped raise the issues reaching beyond the VU and beyond criticisms of its executive board:

[I]t is positive that public debate . . is starting to focus on how we go about higher education, what we think of higher education in the Netherlands. And whether we are willing to invest serious money in higher education or not. And I think that is a very important debate.

At lower organizational levels, the dean of a particularly active faculty, in terms of overt opposition to change at the university, for example, stated that he essentially considered his concerned employees loyal and therefore appreciated their efforts:

I'm not saying that I buy it all or that I also buy the solution, because [the VVU'ers'] problem is much bigger than the problem of the VU. It's just that the VU is now in the limelight, and because you're [i.e., the employees] so loyal and concerned here and now, this is where you speak up.

At the same time, some members of the resistance movement realized that the university management might have been right in at least some of their ideas. The chair of the works council, for example, said:

There's also always a secret opinion that maybe the executive board has a good point.

And the deans are saying, yes, maybe we should do with less money in support. And, even as the works council, we said, if there's inefficiency in administration and so on, it's OK to make it more efficient, and yes, consequently fewer people will work there.

Despite all the schisms, differences, and contradictions, partial or temporary alliances, and what some of the interviewees even considered betrayals, a member of support staff, an active trade union member, and a VVU'er maintained, 'Together we all need each other very much. It's funny to say this. [laughs] We can't do with and we can't do without!'

\section{Discussion}

Both cases analysed illustrate that organizations and their cultures can be understood as constant 'struggle[s] for hegemony' (Parker 2000, 75) in a series of oppositions, which can escalate in schismogenetic processes as described by Bateson (1935). The latter emerge due to differences within one or between different communities, and in these cases they have proved to result in what Bateson calls 'dynamic equilibrium' (179). In this sense, our observations are closely related to Martin Parker's (1995) study of the organizational culture of the Vulcan company [not a real name]. On the basis of ethnographic findings about constantly restructured internal 
coalitions in the organization, Parker suggests leaving behind the prevailing and outdated view of culture as a 'homogenous normative glue'. Instead, organizational culture should be conceptualized as a 'set of factions and alliances' that allow its members to see themselves in certain times as within the 'family' and in certain times as within other 'families' (Parker 1995, 542). Similar views are introduced in parts of Martin's (2002) and Demers's (2007) works, who show that organizational cultures and their transformations need to be understood by fully taking their complexities into account. This article introduces an approach that allows and indeed supports such a notion of organizational cultures; namely, deconstruction. In both cases presented, we noticed that the cultures of an organization are constituted and (de)constructed through oppositions, as suggested by Derrida ([1967] 1998). It was shown that different groups of organizational members tried to bring forward different aspects of their organizations' values and missions. In doing so, inconsistencies presupposed by deconstruction were exposed. However, these inconsistencies proved not to be destructive but instead contributed to the creative maintenance of an equilibrium.

Such a 'deconstructive' understanding of organizational cultures has important implications for managing change. In the DOPPS and at the VU, managers had to accept - or at least tried to understand - complex internal dynamics in their organizations. This was far from an ideal-type understanding of organizational culture as a unified whole that can be shaped and transformed by a team of skilled managers or even by a single person: in complex organizations such as the DOPPS and the VU, with flexible and malleable goals and various possible interpretations of their mission statements related to their non-profit nature, managerial approaches to culture- and organization-making that perceive organizational culture as a unifying force (e.g. Deal and Kennedy 1982; Ouchi 1981; Peters and Waterman 1982) do not make much sense. In such complex, fragmented, and dynamic environments, various approaches to creating order out of chaos based on integrative reification of culture and the idea that 'basic assumptions' of an organizational culture (Schein [1985] 1992) can be transformed by managerial decisions might actually be counterproductive. Instead of an integrationist understanding of organizational culture (Martin 2002), other approaches that enable understanding of cultural pluralism and diversity within an organization (in Martin's [2002] scheme these perspectives are differentiation and fragmentation) are more appropriate to support the necessary cultural shift to non-managerial alternatives (see Parker 2002). Following such approaches, a manager should in a way become his or her own antidote, an 'anti-manager', able to identify, track, and steer - and not only supervise, control, and direct - dynamic change processes in organizations.

\section{Conclusion}

Building on the ideas of cultural schismogenesis and creative deconstruction in organizations, this article analysed two organizations: a Slovenian birdwatching association, the DOPPS, and a Dutch university, the VU. The latter is a much larger and more complex institution than the DOPPS, which is a relatively small national association. Their core activities are also quite different: whereas the VU is an educational and research organization, the DOPPS is involved in nature monitoring and conservation. Our study focused on the transformations that took place within the two organizations and identified several similarities relevant to understanding the dynamics of cultural schismogeneses and consequent organizational transformations. Both entities presented are non-profit organizations and their mission statements go beyond maximization of capital, which may result in conflicted perceptions of organizational goals. In addition, both organizations have faced multiple schisms and have been internally 'torn apart'. 
The article explained that such processes are nonetheless not necessarily counterproductive because they stimulate the organization to transform and adapt to members' needs and broader social, economic, and political demands. As members seemingly pull in different directions, there are shifts taking place in organizations all the time, and conflicts prompt new ideas and test possibilities for further organizational development.

In both cases, different organizational members have referred to dissimilar, and sometimes even contradictory, frames of reference creating organizational settings wherein schisms actually enabled the maintenance of organizational balance. The DOPPS was founded as a volunteer amateur association. During its transition to a more professionalized organization, conflicting views emerged regarding its mission. The consequent schisms were related to the differences in the professional status of organizational members (professionals and volunteers), to the generational gap (older and younger members), to location variations (centre and periphery), and to differences in skills and knowledge (experts and amateurs). As a university, the VU traditionally subscribed to academic values usually defined in terms of collegial governance arrangements and academic freedom. A shift towards managerial values has resulted not only in a schism between employees and management, but also in schisms related to different employment statuses or category of organizational membership (academic staff, non-academic staff, and students), membership in official employee representative bodies (trade unions and the works council), organizational unit membership (particular faculties and support service units), and political affiliation. Although new organizational structures were introduced (a more professional one in the case of the DOPPS and a more managerial, top-down arrangement in the case of the VU), several different organizational goals and missions persisted. Despite the presence of different and often contradicting organizational cultures, which originated from different perceptions of organizational values, both organizations have maintained - sometimes more and sometimes less - a stable balance. We argue that because deconstruction allows for different perceptions of set phenomena, it necessarily also implies a creative combination of these points of views, which ultimately enables organizational adaptation and growth.

This text contributes to our understanding of cultural schisms within organizations in terms of processes of creative deconstruction, as metaphorically illustrated by M. C. Escher's woodcut print Metamorphosis II, and offers insights relevant for organizational change management. The two ethnographic studies further imply two particularly interesting avenues for future research. First, the study shows that boundaries between conflicting groups are unclear and malleable. Individuals may simultaneously belong to various groups and thus operate on what can be argued to be conflicting sides (e.g. individuals taking on both professional and volunteer activities at the DOPPS, or academic middle managers, such as deans, who identify themselves with both academic and managerial values in the case of the VU). Due to their ambiguous position, such individuals may act as 'connectors', transcending cultural divisions and blurring boundaries between different groups. Our data suggest that such 'organizational amphibians' may be important change agents in organizations where organizational goals tend to be ambiguously interpreted, and thus they and their practices deserve closer observation. Second, the cases presented show that schismogenetic processes in organizations are not initiated exclusively 'from within': internal differentiations and consequent transformations of organizational cultures are influenced by broader social, political, and economic contexts. The case of the DOPPS presents how a social and political shift, establishment of a new country, and changed attitudes towards nature conservation activities affected the transformations of the association's culture(s). The 
case of the VU similarly illustrates how national-level budget cuts and new managerial approaches reverberated at the organizational level. These findings raise noteworthy questions related to, first, how the 'old' and the 'newly introduced' organizational cultures influenced by socio-political context interact within organizations and, second, how particular organizational distinguishing features may act in return on broader societal discourses in the course of organizational change.

\section{Acknowledgements}

We would like to thank the members and employees of the DOPPS and the employees and students of the VU for sharing valuable information with us. Our thanks also go to the reviewers for their constructive comments.

\section{Funding}

This work was partly supported by the EU 6th Framework Programme project EuMon, funded by the European Commission [grant number 6463], and the Research Foundation - Flanders (FWO) [grant number G.OC42.13N].

\section{Disclosure statement}

No potential conflict of interest was reported by the authors.

\section{References}

Ahačič, M. 2008. "Ptic nisem nikdar opazoval in proučeval za kratek čas [I have never carried out birdwatching and studied birds merely as a hobby]." Svet ptic 14 (2): 38-40.

Alvesson, M. 1993. Cultural Perspectives on Organizations. Cambridge: Cambridge University Press.

Bal, E., E. Grassiani, and K. Kirk. 2014. "Neoliberal Individualism in Dutch Universities: Teaching and Learning Anthropology in an Insecure Environment." Learning and Teaching 7 (3): 46-72. doi:10.3167/latiss.2014.070303.

Bateson, G. 1935. "Culture Contact and Schismogenesis." Man 35: 178-183. http://www.jstor.org/stable/2789408.

Batteau, A. W. 2000. "Negations and Ambiguities in the Cultures of Organization." American Anthropologist 102 (4): 726-740. doi:10.1525/aa.2000.102.4.726.

Biggart, N. W. 1977. "The Creative-Destructive Process of Organizational Change: The Case of the Post Office." Administrative Science Quarterly 22 (2): 410-426. doi:10.2307/2392181.

Blackwell Reference Online. 2014. Schismogenesis. Accessed June 26, 2015. http://www.blackwellreference.com/public/tocnode?id=g9781444332094_chunk_g97814443320 9422_ss1-27.

Boje, D. M. 1995. "Stories of the Storytelling Organization: A Postmodern Analysis of Disney as 'Tamara-Land'." Academy of Management Journal 38 (4): 997-1035. doi:10.2307/256618. 
Brooks, I. 1999. "For Whom the Bell Tolls: An Ethnography of a Night Nurse Sub-Culture." Studies in Cultures, Organizations and Societies 5 (2): 347-369. doi:10.1080/10245289908523532.

Carrithers, M. 1992. Why Humans Have Cultures: Explaining Anthropology and Social Diversity. Oxford: Oxford University Press.

Cule, P. E., and D. Robey. 2004. "A Dual-Motor, Constructive Process Model of Organizational Transition.” Organization Studies 25 (2): 229-260. doi:10.1177/0170840604040037.

Czarniawska-Joerges, B. 1992. Exploring Complex Organizations: A Cultural Perspective. Newbury Park: Sage.

Daft, R., and K. Weick. 1984. "Toward a Model of Organizations as Interpretation Systems." Academy of Management Review 9 (2): 284-295. doi:10.5465/AMR.1984.4277657.

Deal, T. E., and A. A. Kennedy. 1982. Corporate Cultures: The Rites and Rituals of Corporate Life. Reading: Addison-Wesley.

De Boer, H. F., J. Enders, and L. Leisyte. 2007. "Public Sector Reform in Dutch Higher Education: The Organizational Transformation of the University." Public Administration 85 (1): 27-46. doi:10.1111/j.1467-9299.2007.00632.x.

Demers, C. 2007. Organizational Change Theories: A Synthesis. Thousand Oaks: Sage.

Derrida, J. [1967] 1998. Of Grammatology. Baltimore: Johns Hopkins University Press.

De Vita, G., and P. Case. 2014. "The Smell of the Place': Managerialist Culture in Contemporary UK Business Schools." Culture and Organization (ahead-of-print) 1-17. doi:10.1080/14759551.2014.971122.

DeWalt, K. M., and B. R. DeWalt. 2002. Participant Observation: A Guide for Fieldworkers. Walnut Creek: Altamira Press.

Drucker, Peter. 1990. Managing the Non-Profit Organization: Practices and Principles. New York: HarperCollins.

Garsten, C. 1994. Apple World: Core and Periphery in a Transnational Organizational Culture. Stockholm: Stockholm University.

Gibbs, G. R. 2007. Analyzing Qualitative Data. Los Angeles: Sage.

Gorup, M. 2013. “Beyond the Cookie Factory': Ways of Collectively Resisting New Public Management at VU University Amsterdam." Unpublished master thesis, VU University, Amsterdam. 
Gregory, K. L. 1983. "Native-View Paradigms: Multiple Cultures and Culture Conflicts in Organizations.” Administrative Science Quarterly 28 (3): 359-376. doi:10.2307/2392247.

Hatch, M. J. 1993. “The Dynamics of Organizational Culture.” Academy of Management Review 18 (4): 657-693. doi:10.5465/AMR.1993.9402210154.

Hatch, M. J. 1999. "Exploring the Empty Spaces of Organizing: How Improvisational Jazz Helps Redescribe Organizational Structure." Organizational Studies 20 (1): 75-100. doi:10.1177/0170840699201004.

Kickert, W. 1995. "Steering at a Distance: A New Paradigm of Public Governance in Dutch Higher Education." Governance 8 (1): 135-157. doi:10.1111/j.1468-0491.1995.tb00202.x.

Kuper, A. 1999. Culture: The Anthropologists' Account. Cambridge, MA: Harvard University Press.

Lastovicka, J. L., and K. V. Fernandez. 2005. "Three Paths to Disposition: The Movement of Meaningful Possessions to Strangers." Journal of Consumer Research 31 (4): 813-823. doi:10.1086/426616.

Martin, J. 2002. Organizational Culture: Mapping the Terrain. Thousand Oaks: Sage. Morgan, G. 1981. "The Schismatic Metaphor and Its Implications for Organizational Analysis." Organization Studies 2 (1): 23-44. doi:10.1177/017084068100200103.

Ouchi, W. 1981. Theory Z: How American Business Can Meet the Japanese Challenge. Reading, MA: Addison-Wesley.

Parker, M. 1995. "Working Together, Working Apart: Management Culture in a Manufacturing Firm." The Sociological Review 43 (3): 518-547. doi:10.1111/j.1467-954X.1995.tb00614.x.

Parker, M. 2000. Organizational Culture and Identity: Unity and Division at Work. London: Sage.

Parker, M. 2002. Against Management. Cambridge: Polity and Blackwell.

Peters, J. T., and H. R. Waterman. 1982. In Search of Excellence: Lessons from America's BestRun Companies. New York: Harper \& Row.

Pettigrew, A. M. 1979. “On Studying Organizational Cultures.” Administrative Science Quarterly 24: 570-581. doi:10.2307/2392363.

Podjed, D. 2010a. "Multiple Paradigm Research on Organisational Culture: An Introduction of Complexity Paradigm." Organizacija 44 (1): 11-21. doi:10.2478/v10051-011-0002-0.

Podjed, D. 2010b. “Organizacijski kristal: Karizmatični vodja kot pobudnik prostovoljstva v organizaciji [Organizational crystal: Charismatic leader as an initiator of volunteering in an organization].” Traditiones 39 (2): 7-23. doi:10.3986/Traditio2010390207. 
Podjed, D. 2011. Opazovanje opazovalcev: Antropološki pogled na ornitološko organizacijo [Observing the observers: Anthropological view on the ornithological organization]. Ljubljana: Scientific Publishing House of the University of Ljubljana, Faculty of Arts.

Podjed, D. 2013. "De l'observation à la protection des oiseaux: Le tournant vers la protection de la nature chez les ornithologues amateurs slovènes. [From collecting to protecting birds: The turn of Slovenian amateur ornithology to nature conservation]." Revue d'Anthropologie des Connaissances 7 (2): 113-135. doi:10.3917/rac.019.0461.

Podjed, D., and R. Muršič. 2008. "Dialectical Relations Between Professionals and Volunteers in a Biodiversity Monitoring Organisation." Biodiversity and Conservation 17 (14): 3471-3483. doi:10.1007/s10531-008-9443-Z.

Pollitt, C., and G. Bouckaert. 2004. Public Management Reform: A Comparative Analysis. $2^{\text {nd }}$ ed. New York: Oxford University Press.

Prasad, P. 2005. Crafting Qualitative Research: Working in the Postpositivist Traditions. New York: M. E. Sharpe.

Rosen, M. 2000. Turning Words, Spinning Worlds: Chapters in Organizational Ethnography. Amsterdam: Harwood Academic.

Schein, E. H. [1985] 1992. Organizational Culture and Leadership. 2nd ed. San Francisco: Jossey-Bass.

Schilp, M. 2013. "Rector Lex Bouter legt functie neer" [Rector Lex Bouter resigns]. Ad Valvas, March 28. Accessed May 20, 2014. http://www.advalvas.vu.nl/nieuws/rector-lex-bouter-legtfunctie-neer.

Schumpeter, J. A. [1942] 2003. Capitalism, Socialism and Democracy. London: Routledge.

Strøm, A., and M. S. Fagermoen. 2012. "Systematic Data Integration - A Method for Combined Analyses of Field Notes and Interview Texts." International Journal of Qualitative Methods 11 (5): 534-546.

Taylor, S. 2001. "Locating and Conducting Discourse Analytic Research.” In Discourse as Data: A Guide for Analysis, edited by M. Wetherell, S. Taylor, and S. Yates, 5-48. London: Sage.

Trontelj, P. 1999. "Dobrodošlica novim članicam in članom DOPPS [Welcome to new DOPPS members]." Novice DOPPS 5 (2): 1.

Westerheijden, D. F., H. De Boer, and J. Enders. 2009. "Netherlands: An 'Echternach' Procession in Different Directions: Oscillating Steps Towards Reform." In University Governance: Western European Comparative Perspectives, edited by C. Paradeise, E. Reale, I. Bleiklie, and E. Ferlie, 103-125. Dordrecht: Springer. 
Wiener, N. [1950] 1954. The Human Use of Human Beings: Cybernetics and Society. New York: Doubleday.

Ybema, S., D. Yanow, H. Wels, and F. Kamsteeg. 2009. "Studying Everyday Organizational Life." In Organizational Ethnography: Studying the Complexities of Everyday Life, edited by S. Ybema, D. Yanow, H. Wels, and F. Kamsteeg, 1-20. Los Angeles: Sage. 